\title{
Covert postpartum urinary retention
}

\author{
Dolezal P, Zahumensky J, Otapkova P, Papcun P, Krizko Jr M \\ 2nd Department of Obstetrics and Gynecology, University hospital Bratislava, Faculty of Medicine, \\ Comenius University Bratislava, Slovakia, Bratislava, Slovakia. jozef.zahumensky@gmail.com
}

\begin{abstract}
OBJECTIVES: This study was conducted to determine the frequency of increased postvoiding residual volumes (PVRV) 3 days after delivery and to examine the associated risk factors.

BACKGROUND: Increased PVRV - covert postpartum urinary retention, is an asymptomatic condition with possible long-term adverse effects. While early diagnosis and appropriate management can avoid long-term complications, screening is not routinely performed. By identifying risk factors, we could define the group of patients suitable for screening.

MATERIAL AND METHODS: This was a prospective observational study carried out over a 3-month period at the university teaching hospital in Bratislava, Slovakia. All participants underwent ultrasound determination of PVRV while $80 \mathrm{ml}$ and more on day 3 was considered pathological.

RESULTS: A total of 429 women were included in the study. The prevalence of covert post-partum urinary retention was $9.2 \%$. Assisted vaginal delivery (ventouse, forceps) and episiotomy were risk factors for postpartum urinary retention (18.7 \% vs $6.1 \% ; p=0.0053 ; 52.1 \%$ vs $35.7 \% ; p=0.0483$; respectively).

CONCLUSION: Our observations confirmed the existence of PVRV of $80 \mathrm{ml}$ and more on day 3 in almost $10 \%$ of women who had delivered at our clinic. The results of our study prove that instrumental delivery represents a considerable obstetrical-pediatric risk factor for PVRV. Our data support the need of adopting a risk-factor-based approach to PVRV screening as part of postpartum bladder care (Tab. 2, Fig. 1, Ref. 12). Text in PDF www.elis.sk.

KEY WORDS: labor, vaginal delivery, urinary retention, instrumental delivery, episiotomy, voiding difficulty.
\end{abstract}

\section{Introduction}

Postpartum urinary retention (PUR) is a common condition in the immediate postpartum period with incidence ranging from 1.5-30\% (1-3). According to clinical demonstration it can be classified either as overt or covert form. The former is defined as the inability to void spontaneously within 6 hours of either vaginal delivery or catheter removal after delivery. The covert form can be identified by elevated post-void residual volume measurements, either with ultrasound scanning or with catheterization after urination. The exact cut-off value is debated, usually women with post-void residual volumes of more than 100 or $150 \mathrm{ml}$ and no symptoms of urinary retention are in this category (2). Overt or symptomatic urinary retention is easily detectable owing to its clear clinical appearance, and therefore is adequately treated, whereas the covert form stays undiagnosed in most cases, while screening in the postpartum period is not routinely provided. Although there is not enough evidence for long-term adverse effects of covert

2nd Department of Obstetrics and Gynecology, University hospital Bratislava, Faculty of Medicine, Comenius University Bratislava, Slovakia, Bratislava, Slovakia

Address for correspondence: J. Zahumensky, MD, PhD, 2nd Department of Obstetrics and Gynecology, University hospital Bratislava, Faculty of Medicine, Comenius University Bratislava, Slovakia, Ruzinovska 6, SK-826 06 Bratislava, Slovakia.

Phone: +421.918900860 urinary retention, it is known that even a single episode of overdistension of urinary bladder can lead to long-term voiding difficulties, recurrent urinary tract infections and, rarely, to impaired renal function $(4,5)$. They are not associated with mortality but its morbidity is significant. By identifying the risk factors of asymptomatic urinary retention, we could asses a prognostic model to select a group of patients at high risk of urinary retention, and design a guideline for screening and intervention to prevent this condition and its adverse effects.

\section{Material and methods}

This study was an observational prospective study. Ethical clearance was obtained from the Institutional Ethical Review Committee. Between February 2018 and April 2018, all sui iuris women giving birth to full-term singletons after uncomplicated pregnancies and willing to participate in this study were included. Informed consent was obtained from the parturient. Patient's refusal to participate in the study was respected with no attempt at coercion or inducement to gain consent. All included women underwent ultrasound determination (GE Voluson S6) of postvoiding bladder volumes postpartum on day 3 , on day of discharge from the maternity ward, after spontaneous micturition. Ultrasound examination protocol was integrated with delivery-related data from medical documentation. The study group was divided into case and controls groups. Data are presented as means or numbers (as 


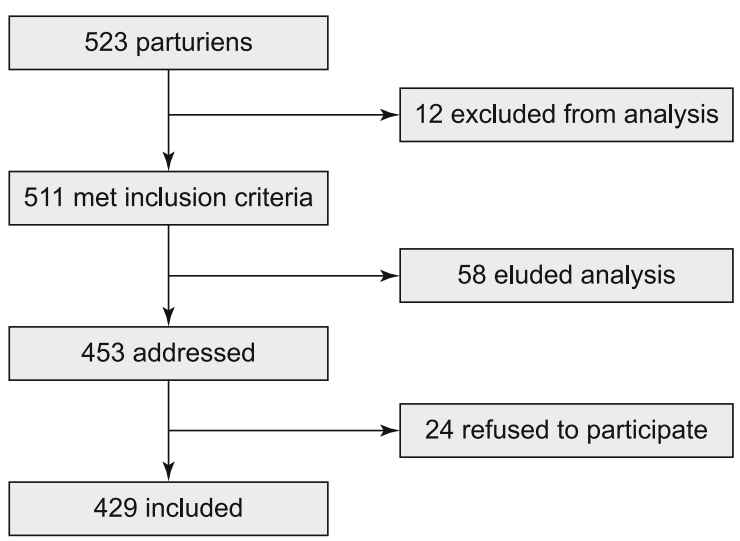

Fig. 1 Patient data flow.

percentages). Student's t-test or Fisher's exact test were used to assess the potential relationships between post-voiding residual volume of more than $80 \mathrm{ml}$ on the third postpartum day and each of the following obstetrical covariables, namely age, parity, body mass index, mode of delivery, instrumental extraction, episiotomy, degree of perineal tears, and infant's birth weight. All data were

Tab. 1. Characteristics of the study group.

\begin{tabular}{lcc}
\hline & $\mathrm{n}$ & $\%$ \\
\hline Age - mean & 30.6 & \\
35 and older & 87 & 20.3 \\
Primiparous & 295 & 68.6 \\
BMI & 27.0 & \\
BMI more than 30 & 90 & 21.0 \\
Spontaneous vaginal delivery & 295 & 69.0 \\
Caesarean section & 104 & 24.2 \\
Forceps & 9 & 2.1 \\
Ventouse & 21 & 4.9 \\
Newborn weight - mean & $3413.2(1850-5030)$ & \\
Weight more than 4000 g & 52 & 12.1 \\
No perineal tear & 55 & 12.8 \\
Episotomy & 177 & 54.6 \\
3rd and 4th degree tear & 9 & 2.1 \\
\hline
\end{tabular}

analyzed using statistical tools of Microsoft Excel software and online software Medcalc.

\section{Results}

In this period, out of 523 women who gave birth at our clinic, 511 met the inclusion criteria, 58 eluded analysis, and 24 refused to participate. Finally, 429 women were included in the study (Fig. 1). Table 1 shows basic characteristics of the group. We have set the cut-off value at $80 \mathrm{ml}$, which is one SD above the mean. Forty-eight women with volumes over this value were referred to as the case group, 277 women with no postvoiding residuum were labelled as controls. The individual risk factors of occurrence of covert postpartum urinary retention are shown in Table 2.

The average age was 29.8 in women with retention and 30.8 in the control group, the difference was not significant. The mean birth weight of infants for women with PUR was 3552.3 $\mathrm{g}$ (2.510-4.610 $\mathrm{g}$ ), which was comparable to the mean birth weight of $3.372 \mathrm{~g}$ (1.850-5.030 g) for women without retention; the count of macrosomic fetuses (more than $4.000 \mathrm{~g}$ ) was comparable in both groups and not a significant risk factor $(\mathrm{p}=0.8058)$. Overall, primigravidae constituted $75.0 \%$ of case group, compared with $67.14 \%$ in control group, thus, the parity was not associated with PUR ( $p=$ 0.3169 ). As for operational vaginal delivery, the difference was significant ( $\mathrm{p}=0.0053$ ), thus confirming it to be an isolated risk factor, with RR of 3.0 (95\% CI, 1.44-6.45). Epistosiotomy yielded RR of 1.38 (95\% CI 1.06-1.80). Labor without any perineal tear is a protective factor for postpartum urinary retention $(\mathrm{p}=0.0082$, RR 0.22 (CI 0.05-088)), in our cohort.

\section{Discussion}

The incidence of increased post-void residual volume in our unit reported by this study was $9.2 \%$, no participant developed acute urinary retention. Assisted vaginal delivery and mediolateral episiotomy are risk factors that are associated with increased PVRV at our unit. These risk factors contribute to physiological changes following pregnancy and increase probability of postpartum urinary retention. Mechanical trauma from instrumen-

Tab. 2. Individual risk factors.

\begin{tabular}{|c|c|c|c|c|c|c|}
\hline & \multicolumn{2}{|c|}{ PVRV 80 and more $(n=48)$} & \multicolumn{2}{|c|}{ PVRV $0(n=277)$} & \multirow[b]{2}{*}{$\mathrm{p}$} & \multirow{2}{*}{$\begin{array}{c}\mathrm{RR} \\
(95 \% \text { confidence interval) }\end{array}$} \\
\hline & $\mathrm{n}$ & $\%$ & $\mathrm{n}$ & $\%$ & & \\
\hline Age - mean & 29.8 & & 30.8 & & & \\
\hline 35 and older & 7 & 14.6 & 64 & 23.1 & 0.2556 & \\
\hline Primiparous & 36 & 75 & 186 & 67.14 & 0.3169 & \\
\hline BMI & 27.9 & & 27.2 & & & \\
\hline BMI more than 30 & 11 & 229 & 65 & 23.5 & 0.8508 & \\
\hline Spontaneous vaginal delivery & 28 & 58.3 & 185 & 66.8 & 0.2550 & \\
\hline Caesarean section & 11 & 22.9 & 65 & 23.5 & 0.8508 & \\
\hline Forceps & 3 & 6.2 & 4 & 1.4 & 0.0688 & \\
\hline Ventouse & 6 & 12.5 & 13 & 4.7 & 0.0451 & \\
\hline Instrumental delivery (forceps + ventouse) & 9 & 18.7 & 17 & 6.1 & 0.0053 & $3.0(1.44-6.45)$ \\
\hline Newborn weight mean & 3552.3 & & 3372.6 & & & \\
\hline More than $4000 \mathrm{~g}$ & 6 & 12.5 & 31 & 11.2 & 0.8058 & \\
\hline No perineal tear & 2 & 4.2 & 49 & 17.7 & 0.0082 & $0.22(0.05-0.88)$ \\
\hline Episiotomy & 25 & 52.1 & 99 & 35.7 & 0.0483 & $1.38(1.06-1.80)$ \\
\hline
\end{tabular}


tal delivery can lead to aggravated perineal edema that restrains bladder voiding. The pudendal nerve damage occurring during instrumental deliveries can impair afferent innervation of urinary bladder and obstruct the relaxation of pelvic floor muscles and urethral sphincter (6). This nerve damage is generally temporary and unlikely to cause chronic retention. Instrumental birth may be associated with other factors such as prolonged labor, epidural analgesia, parity and episiotomy, making it questionable whether it is an independent predictor. (7) The mediolateral episiotomy, as a predictor, is likely to exert its effect through the development of pain (from the suture) and subsequent disturbance in bladder sensitivity as well as via central inhibition of bladder function (8).

Although this was a study with data from over 400 women on PVRV after delivery, some potential limitations need to be discussed. There is no accordance in the literature for the cut-off value of PVRV when defining covert PUR. Values of $100 \mathrm{ml}, 150$ $\mathrm{ml}$ or even $250 \mathrm{ml}$ are used. Most commonly, the value of 150 $\mathrm{ml}$ is used. This value would facilitate the comparison with other studies, however in our cohort, there was only a small number of women with PVRV of more than $150 \mathrm{ml}$ and taking this group as cases would lower the significance of statistical analysis. Secondly, the use of ultrasound as a technique for measuring PVRV has often been discussed. The use of catheterization to measure the volume of urine remaining in the bladder is a more accurate method. However, with personnel well-trained in using ultrasound, the inaccuracy could be lowered to $10 \%$ (9). The main reason of using ultrasound is that it is non-invasive, comfortable, painless, quick and safe. There are studies approving the use of ultrasound with different volume-calculating formulae as an accurate method, which could be used for the assessment of PVRV (10). Finally, including primipara only could cleanse the data from obstetrical covariables acquired from previous childbirths and help us identify risk factors more accurately.

One of the largest studies concerning this subject is a 2014 study by Buchanan and Beckmann who found that primiparity and large perineal tears as well as caesarean section are independent predictors (11). Other authors add a prolonged first or second phase of labor, use of epidural analgesia, and macrosomic fetus to the list of risk factors for urinary retention Although several authors have shown that PVRV often normalizes spontaneously (1, $2,12)$, the data on long-term and adverse effects are still missing.

\section{Conclusion}

Covert postpartum urinary retention is a common condition involving almost $10 \%$ of women in our population. It remains a relatively poorly defined and understood condition, and yet can result in significantly short and potentially long-term complications if it goes unrecognized. The strong evidence given by this study
(RR 3.0) supports the thesis that instrumental delivery should be considered a dominant risk factor. Women undergoing instrumental delivery deserve attentive bladder care during labor and vigilance in the early postpartum period, in order to detect and manage different bladder conditions and prevent further complications. We acknowledge the need of further research and after this pilot study we are in the process of carrying out a longer prospective study PAREZ with more primiparous women involved, longer follow-up period, and more detailed approach.

\section{References}

1. Kekre AN, Vijayanand S, Dasgupta R, Kekre N. Postpartum urinary retention after vaginal delivery. Int J Gynaecol Obstet 2011; 112 (2): 112-115.

2. Yip SK, Brieger G, Hin LY, Chung T. Urinary retention in the postpartum period. The relationship between obstetric factors and the postpartum post-void residual bladder volume. Acta Obstet Gynecol Scand 1997; 76 (7): 667-672.

3. Ajenifuja KO, Oyetunji IO, Orji EO, Adepiti CA, Loto OM, Tijani MA et al. Post-partum urinary retention in a teaching hospital in southwestern Nigeria. J Obstet Gynaecol Res 2013; 39 (8): 1308-1313.

4. Bross S, Schumacher S, Scheepe JR, Zendler S, Braun PM, Alken P et al. Effects of acute urinary bladder overdistension on bladder response during sacral neurostimulation. Eur Urol 1999; 36 (4): 354-359.

5. Mustonen S, Ala-Houhala IO, Tammela TL. Long-term renal dysfunction in patients with acute urinary retention. Scand J Urol Nephrol 2001; 35 (1): 44-48.

6. Chaliha C. Postpartum bladder dysfunction. Rev Gynaec Perinat Practice 2006; 6 (3): 133-139.

7. Mulder FE, Schoffelmeer MA, Hakvoort RA, Limpens J, Mol BW, van der Post JA et al. Risk factors for postpartum urinary retention: a systematic review and meta-analysis. BJOG 2012; 119 (12): 1440-1446.

8. Mulder FE, Oude Rengerink K, van der Post JA, Hakvoort RA, Roovers JP. Delivery-related risk factors for covert postpartum urinary retention after vaginal delivery. Int Urogynecol J 2016; 27 (1): 55-60.

9. Weissman A, Grisaru D, Shenhav M, Peyser RM, Jaffa AJ. Postpartum surveillance of urinary retention by ultrasonography: the effect of epidural analgesia. Ultrasound Obstet Gynecol 1995; 6 (2): 130-134.

10. Yip SK, Sahota D, Chang AM. Determining the reliability of ultrasound measurements and the validity of the formulae for ultrasound estimation of postvoid residual bladder volume in postpartum women. Neurourol Urodyn 2003; 22 (3): 255-260.

11. Buchanan J, Beckmann M. Postpartum voiding dysfunction: identifying the risk factors. Aust NZ J Obstet Gynaecol 2014; 54 (1): 41-45.

12. Hée P, Lose G, Beier-Holgersen R, Engdahl E, Falkenløve P. Postpartum voiding in the primiparous after vaginal delivery. Int Urogynecol J 1992; 3 (2): 95-99. 